\title{
Considerations about Teaching Reform of Electric Machinery and Drive Course
}

\author{
Caihong Zhu ${ }^{1, a^{*}}$ and Hongtao Zhang ${ }^{1, b}$ \\ ${ }^{1}$ Suzhou Vocational University, Suzhou, China \\ azhuzhang_2000@163.com, bzch@jssvc.edu.cn
}

\begin{abstract}
Keywords: Electric machinery and drive; Teaching reform; Multi-media courseware; Examination bank; Experiment teaching
\end{abstract}

\begin{abstract}
Electric machinery and drive" is one of the important basic courses of the department of electric engineering and relevant professional. Through analyzing the current teaching state of the course, the author has put forward the method of solving problem in these respects of strengthening the personal qualities of a teacher, teaching contents, teaching methods, and reforming the testing methods. The solution of these problems will improve the teaching level, and the teaching quality greatly.
\end{abstract}

\section{Introduction}

"Electric Machinery and Drive" is a combination of two courses of "Electric Machinery" and "Electric Driving". It is a basic course of electric automation and its related specialty[1], which is characterized by strong theoretical and comparatively wide Engineering background, which is difficult to teach and more difficult to learn. In traditional classroom teaching, the teaching mode of "teacher blackboard - student" or "teacher - electronic lesson plan - student" is generally adopted, and "teaching" and "learning" are difficult to be well coordinated in the classroom, as a result, it's difficult to timely and effective digestion of teaching content, and the teaching effect is affected, so the weak students feel that this course is difficult to learn. In experimental teaching, it is difficult to cover all the knowledge points relying on the existing hardware experimental conditions, and the teaching effect is not very good, which can not to consolidate classroom knowledge and improve the students' practice and innovation ability of the expected results. Therefore, it is necessary to renew the concept and establish a full range of new teaching system including theory teaching, computer-aided instruction and practice teaching, and fully mobilize the enthusiasm of both teachers and students.

\section{Improving the Quality of Teachers}

The basic task of teaching reform is to develop students with the ability to acquire new knowledge and new methods, and to cultivate students with good innovative thinking quality. Knowledge-based economy and innovative society which has put forward higher requirements for teachers [2], and given the teacher more responsibility. Teachers must scientifically understand the relationship between teaching and learning, correctly handle the practice of teaching and learning process, an update the concept of education of students first, teaching first, service first to organization and implementation of education and teaching activities, not from the past "experience" to "research", and from knowledge "providers" to "guidance". Teachers should follow the teaching methods, continue to study the forefront of disciplines, broaden the teaching content, reform the traditional teaching methods, and strive to become a research teacher, which is the development needs of the times. Only the research-typed teachers can competent for education teaching work, and to create high-quality talents to adapt to The Times demand.

\section{Adjusting the Teaching Content}

Restricted by total credit hours [3], the optimization of teaching contents and reconstruction is imperative, and the necessary way of curriculum reform. First of all, it should start from the adjustment 
of teaching materials, for example, the traditional textbooks attached the great importance to the rigorous and integrity. The rigorous theoretical derivation of the motor is necessary to conduct in-depth study, but enough vocational schools in the theory of good teaching purposes, the long deduction may increase the psychological fear of the students. If a particular step didn't listen to clear, it will affect the back of the study, so some deduction can be considered in the appendix of the book or on the reference books, the text mainly gives the analysis (derivation) thinking, analysis, conclusion, in this way, students way of thinking is clear, easy to catch the point. And improve the quality of illustrations in the textbook will help students to understand the relevant concept, which mainly refers to two aspects, one is to use more appropriate, more illustrative illustration of the problem; the second is to improve the quality of illustrations, the concept of space is the motor very strong, a lot of students on this course before did not read the motor, such as motor structure, and the rotating magnetic field concepts, students are difficult to set up in the brain. If Textbooks with clear three-dimensional graphics, especially accompanied by a small amount of color illustrations (photos), for beginners is very important, which can greatly improve the efficiency of teaching.

Specifically: (1) Change the arrangement of the dc motor and three-phase asynchronous motor, highlight the contents of three-phase asynchronous motor. (2) Delete some cumbersome theoretical derivation, such as the deletion of three-phase asynchronous motor rotating magnetic field mathematical formula, using intuitive diagram to explain. As long as the students have the most basic knowledge of electromagnetic induction law, who can master the theory of rotating magnetic field.(3) teach the transformer and three-phase asynchronous motor equivalent circuit, which can be directly given the equivalent circuit diagram, without winding conversion and frequency conversion (transformer only winding conversion). And then, according to their structure to explain the meaning of the amount of each line diagram. (4)In the teaching of basic theory, the theoretical knowledge combined with the actual example for production and living, which can deepen students' mastery of basic theory of knowledge through case analysis.

\section{Improving Teaching Methods}

On the higher vocational colleges, the quality of students is good or bad, the practice ability of high and low is the school's "life" $[4,5]$. Therefore, teachers should actively improve teaching methods, in order to maximize students' actual analysis, problem solving skills, improve the beginning ability, so that the students can adapt to meet the requirements of social development for professionals.

In the traditional teaching activities, the teacher's main task is to explain the concept, the theorem and the proof of teaching materials. The student's main task is to understand the concept and principle of factual memory, and the simple application. The effect of teaching is that students acquire knowledge just simple pile of a teacher's classroom teaching content, it is difficult for students to infer and predict the problem based on teachers impart knowledge, and certainly not to explain the phenomenon and problems. The current teaching reform focuses on the improvement of teaching methods to improve teaching quality. For example, the use of comparative teaching: for beginners, although the motor is difficult to learn, but they are often interrelated, when the various electrical machinery are linked to compare, it can achieve twice the result with half the effort. Relatively speaking, the transformer is relatively simple, students are generally more easily understood what you talk about transformers, and explaining the asynchronous machine can be based on its internal electromagnetic relationship, related to the similarity of the transformer. This not only explained the induction motor, but also deepened the understanding of the transformer. In addition there are DC motor, AC motor comparison; synchronous motor and asynchronous motor comparison. Through this constant comparison, you can let students straighten out the context of knowledge before and after, to deepen the understanding and mastery of knowledge. 


\section{Strengthening Teaching Methods}

As the "Electric Machinery and Drive" course theory is strong, students are easy to feel abstract and empty, which is not conducive to fully mobilize the students interest in learning and subjective initiative, so the introduction of multimedia technology, development of auxiliary teaching software, reducing teaching difficulty, can improve teaching effect, reduce teaching time, improve teaching efficiency [6].The use of multimedia technology with a variety of electrical equipment and its main components made of the other images, video or animation, can explain the motor principle, express the image of the motor to increase the perceptual knowledge of students, the effect accompanied by physical is better. Some important and difficult points in electromotor and drag are: AC winding, rotating magnetic field, electromotive force in electromotive force of three-phase asynchronous motor, rational use of computer aided teaching software can optimize the teaching process. In the process of classroom practice, the magnetic field and magnetic potential waveform of the electrical machinery show in the process of human-computer interaction; Under the mouse click to choose the structure of the machine under the function of multimedia animation to decompose step by step assembly, or repeat, can need not language, can make the students to see their shape and the kernel, the stator, rotor, coil and magnetic field, the trend of the current visualization teaching can let students perceptual knowledge in a short time, and then the potential, current Waveforms decompose fundamental and harmonics by color effects. At this time, the screen showed the students familiar with the formula, characteristic curve and so on, so that students enhance and enrich the correct understanding and interpretation of the relationship between things ability.

For example, when talking about the working principle of DC motors and three-phase asynchronous motors, the students have more intuitive understanding through animation simulation to explain; When speaking their structure and winding, combined with pictures, images, static to dynamic and difficult to Jane, the relationship between the motor part fully to display, at the same time some invisible physical quantities such as current, magnetic field lines into a tangible visual image, can provide students with visual perceptual materials. In short, the use of multimedia courseware to teach " Electric Machinery and Drive "can improve classroom teaching image, vivid, not only to free students from the burden of taking notes, and greatly improve the efficiency of the classroom, stimulate the students' interest in study.

\section{Improving the Experimental Teaching}

"Electric Machinery and Drive" is a practical course, we must strengthen the experimental part of the experimental curriculum reform, focus on improving the cultivation of the student beginning ability [7, 8]. The focus of experimental reform is to strengthen the design of experimental teaching. The traditional experiments are mainly confirmatory experiments, students generally use the circuit diagram on the blackboard by the teacher wiring and correct, then observe the experimental phenomenon of power and measurement of experimental data. To do so, the surface looks fast, less consumables, experimental failure rate is small, but the student initiative is poor. Students do not doubt the correctness of the conclusions of the experimental lecture, so the experiment is only to verify it. So it is unfavorable for students to cultivate the ability to analyze and solve problems. Individual students is not clear the experimental principle, only according to experimental procedures to mechanically connect, measure, record, can also draw conclusions consistent with the experimental lecture. Appropriate to increase the design, comprehensive and exploratory experiments, students are encouraged to complete the basic experimental content under the premise of their own design test content to consolidate and deepen the understanding of the content of teaching. In the course of reform, we adopt the method of class-group experiment, so as to make the students do their own experiment and finish the experiment independently and improve their ability of experiment operation. The teaching methods has a strong intuitive, experimental, purpose, interactive. Students can see their progress, experience the joy of success, and stimulate a strong desire for knowledge, passion to continue after the study and training. 


\section{Reforming Assessment Methods}

The exam questions have a large amount of calculation in the course of "Electric Machinery and Drive", so with a test paper in two hours to determine a student's achievement is not very reasonable, so it is the need for reforms to emphasize and strengthen Students' comprehensive ability training [9]. The examination results are divided into ordinary grades, test scores and practical achievements. The grades account for $20 \%$ of the total score, mainly include the learning attitude, preparation before class, class participation, attendance, learning initiative, and finish the homework and the ability to use professional knowledge to solve problems, etc. In the form of an open-book exam, the teacher have a good test for the construction of the library according to school rules for examination, accounting for $70 \%$ of the total grade. Experiment result according to the attendance, attitude, practice ability and innovation ability, experiment reports to comprehensive evaluation, the experimental results is accounting for $10 \%$ of the grade. In this way, to get good grades, the students will work hard in the usual learning process to promote the change of style of study, only the final exam to obtain high scores is impossible.

\section{Conclusion}

The education idea, training objectives and personnel training model, etc. in the vocational education must be achieved through curriculum teaching. It is a long-term curriculum reform to explore a subject to establish a comprehensive quality-based [10], ability-based guiding ideology. In recent years, the practice has proved that, through the teachers and students in the teaching and learning run-in, the teaching reform of" Electric Machinery and Drive" course, has achieved good teaching effect, and is more suitable for vocational schools modern teaching concept, and the academic performance and practical ability of students have improved. It has laid a professional theoretical foundation for the following courses of automatic control theory, AC / DC speed control system, modern power electronics technology, control motor and so on, and laid a technical foundation for students to work in electrical engineering and other related fields. For example, students take part in the electrical mid-level workers have a pass rate of $90 \%$ or more. Of course, the teaching reform is a long and arduous work, not overnight to complete, it needs unremitting efforts. Only continued to improve, summarized unceasingly, the reform can been constantly improved. The students can be happy and easy to complete the learning task when changing the learning into a fun.

\section{References}

[1] D.L. Guo, Z.C. Jiang and Y.Y. Liu: Journal of the HLJE, Vol. 1194 (2016) No.12, p.5.

[2] H.R. Li: Journal of the ZHSN, Vol. 18 (2016) No.6, p.203.

[3] H. Hu, Z.J. Tao and B.W. Yang: Journal of the HUAS, Vol. 22 (2010) No.4, p.58.

[4] F.J. Zhang, J. Wang: Journal of the HEF, Vol. 16 (2013) No.4, p.16.

[5] G.P. Ye: Electric Machines and Applications (Electronic Industry Press, China 2015).

[6] H.C. Peng: Electric Machinery and Drive (Machinery Industry Press, China 2015).

[7] N. Chen: Journal of the SEAC, Vol. 325 (2015) No.9, p.53.

[8] Information on http:// www.jxgymy.com/cjb/news.

[9] X.Y. Xing, T.P. Liang: Journal of the ZGDLJY, Vol. 331 (2014) No.36, p.94.

[10] O. Song, R. Wang and Y.S. Zhang: Journal of the ZGDLJY, Vol. 328 (2013) No.33, p.123. 